\title{
O capitalismo é também uma máquina imperfeita: uma breve reflexão sobre a axiomatização do capital
}

\author{
ELISSA GABRIELA FERNANDES SANCHES ${ }^{1}$
}

O capitalismo é uma grande e formidável máquina de desejos ${ }^{2}$. Suas engrenagens servem para manipular a libido de modo que a oriente sempre para si próprias, em um processo de feedback positivo, uma retroalimentação. Todavia, quem diria que uma máquina tão aparentemente perfeita teria vazamentos. Este é o problema: nenhuma máquina humana é perfeita (DELEUZE; GUATTARI, 2010, p. 20), pois exigiria que fosse construída por seres que saibam o que é a perfeição. $E$ nestes momentos, nossa finitude possibilita a realização de pequenos milagres, por intermédio dos fluxos libidinais que extravasam da corrente capitalista. São pequenas gotas desviadas, tão ínfimas que quase não danificam o funcionamento mecânico.

No entanto, e se estes fluxos convergirem para uma imensa pressão em alguma das partes da máquina capitalista? O que ocorreria? Suponhamos o movimento hippie, que alcançou seu clímax nos anos sessenta. Em seu auge, representava uma poderosa força maquínica. Vejamos, não se tratava de gotículas, mas de uma pressão de extravasamento que, de tão grande, parecia que qualquer engrenagem não suportaria o seu peso. Não era apenas um indivíduo, mas vários fluxos de desejos diferentes, unidos, de maneira similar ao que aconteceu no aclamado movimento revolucionário de maio de 68, em Paris, na França. Deleuze afirmou em uma entrevista: "O que não foi adequadamente discutido sobre o 'Capital' de Marx se refere ao fato dele ser fascinado por mecanismos capitalistas, precisamente porque $o$ sistema é demente, ainda que funcione muito bem ao mesmo tempo" (informação verbal) $)^{3}$. De fato, o que não imaginamos é o quão complexa esta máquina possa ser,

'Bacharel em Teologia pela FNB e mestranda em Filosofia pela UNIOESTE. E-mail: elissagabrielafs@hotmail.com

${ }^{2}$ A própria análise de Deleuze e Guattari (2010, pp. 297-298; grifos nossos) a respeito do capitalismo como uma grande conjunção de fluxos de desejos, se transformando ele próprio em uma máquina desejante - tendo em vista que ela é, por si só, uma máquina social (socius) - é de grande significação para a compreensão de nosso argumento. O autor fala: "Sempre houve desejos descodificados, desejos de descodificação - a história está cheia deles. Mas acontece que os fluxos descodificados só formam um desejo - desejo que produz em vez de sonhar ou faltar, máquina ao mesmo tempo desejante, social e técnica - pelo seu encontro num lugar, pela sua conjunção num espaço, o que demanda certo tempo. Eis por que o capitalismo e seu corte não se definem simplesmente por fluxos descodificados, mas pela descodificação generalizada dos fluxos, pela nova desterritorialização [266] maciça e pela conjunção de fluxos desterritorializados. [...] a máquina capitalista, a civilizada, vai estabelecer-se, primeiramente, sobre a conjunção". Tais desejos culminam em uma única máxima: a produção (DELEUZE; GUATTARI, 2010, p. 298).

${ }^{3} \mathrm{~A}$ citação foi retirada de uma entrevista. A fala no original é: "Something that hasn't been adequately discussed about Marx's *Capital* is the extent to which he is fascinated by capitalists mechanisms, precisely because the system is demented, yet works very well at the same time" (DELEUZE, 1995). DELEUZE, Gilles. Capitalism: A VerySpecial Delirium: entrevista. [1995]. Chaosophy. Entrevista concedida a SylvereLothringer. Disponível em: http://www.generation-online.org/p/fpdeleuze $7 . h t m$. Acesso em 10 ago. 2016. 
posto que não visualizamos seus limites, sua espontânea capacidade de se reestruturar quando percebe um potencial defeito no manejamento dos fluxos de desejo. Assim, nenhuma dessas forças contra a alienação social - a exemplo do movimento hippie - foram eficazes. Elas fizeram demasiado estardalhaço e, rapidamente, despertaram as engrenagens capitalistas que se ocuparam em reprimilas, cortar seus fluxos, suas ligações externas.

Hoje o movimento hippie é apenas um símbolo, e simbolismos exigem um esforço de interpretação. Qualquer coisa que se torne objeto de uma tarefa hermenêutica significa que está oculto sob uma camada de aparência que nos proíbe o acesso. Neste sentido, um símbolo pode ser nada, ao mesmo tempo em que pode ser qualquer coisa (DELEUZE; GUATTARI, 2010, pp. 272-273). Surge então a pergunta essencial: qual a relevância prática de um evento histórico que necessita ser interpretado? Será que ele ainda pode inspirar novas ações revolucionárias? Poderá ser um novo estopim para o desvio de novos fluxos de desejo em conjunto?

Vamos seguir para uma outra situação, mais recorrente em nosso cotidiano. Um dos fortes mecanismos da máquina capitalista, nos dias atuais, é o famoso estilo de vida "verde". No entanto, tal propaganda nem sempre obteve o aval do sistema que lucrava com o consumo de materiais que passavam longe de qualquer objetivo saudável. Temos como exemplo o fumo de cigarros, consumo de drogas, bebidas alcoólicas. Isso sem considerarmos a quantidade de alimentos que eram - e são ainda - ingeridos diariamente, os quais permanecem insuflados de substâncias tóxicas ao organismo e que nem precisam ser mencionados. No entanto, a partir da década de noventa, uma nova maneira de viver se tornou desejável. Sobreviventes de uma geração que tinha se lançado às odes capitalistas de consumo (não é difícil achar anúncios dessa época glorificando a sofisticação de um fumante) começaram a ir contra a corrente na busca de novas formas de aquisição, que não se reduzissem ao que já estava sendo praticado ${ }^{4}$.

\footnotetext{
${ }^{4} \mathrm{O}$ desenvolvimento desta nova visão de mundo levou ao surgimento de um modelo de inovação disruptiva, conceito este que foi precedido por um outro, bastante similar, chamado modelo de inovação sustentadora, lançado por Clayton Christensen na década de 9o. "As inovações sustentadoras irão resultar em produtos e serviços que atendam as necessidades dos clientes em mercados já estabelecidos, permitindo as empresas aumentarem a sua margem de lucro e vender produtos de maior qualidade, sem precisar assumir grandes riscos" (CÂNDIDO, 2011, p. 6). As inovações disruptivas "apresentam outros atributos que irão chamar atenção dos novos consumidores (menos exigentes), porém ainda nesta fase estes atributos não são muito valorizados pelos consumidores da tecnologia anterior, que são os consumidores mais exigentes. Os novos produtos são normalmente mais baratos, mais simples, menores, com maior praticidade e conveniência para o uso. Portanto, isso dará origem a novos mercados, que poderão facilmente assumir a posição dos produtos existentes anteriormente nos mercados. Assim, com estes diferenciais a tendência é os negócios prosperarem, pois as organizações que desenvolvem a inovação disruptiva ganharão experiência e investimentos sólidos, permitindo que melhorem cada vez mais o desempenho dos seus produtos, aprimorem os atributos existentes e ainda acrescentar novos atributos aos seus produtos" (CÂNDIDO, 2011, p. 7). Um exemplo de inovação disruptiva é o surgimento do Netflix, que se propôs substituir a forma convencional de entretenimento através da própria televisão a cabo e locadoras. Hoje, uma das grandes companhias do mercado,
} 
Que conflito difícil o capitalismo teve que enfrentar, escondendo suas engrenagens mais resistentes, das megaindústrias, que o bancavam. Contudo, ele foi esperto, nós, máquinas desejantes (DELEUZE; GUATTARI, 2010, p. 11), dentes da engrenagem capitalista, nos reorganizamos em função destas novas demandas. A máquina do capital5 se reinventou diante dessas novas exigências, construindo válvulas de escape para reduzir a pressão dos vazamentos que originaram as novas demandas (desvios de fluxos). Entre os sinais de sua renovação, temos, por exemplo, a monetização absurda de alimentos portadores de quantidade reduzida de fertilizantes e pesticidas (orgânicos), bem como a criação de conceitos como "transgênico", "OGMs" (Organismos Geneticamente Modificados) e "sustentável" que estampam as novas embalagens "que não agridem o meio ambiente”.

Pouca coisa é mais capitalista do que a atual defesa de uma forma de viver coerente a uma ideia de sustentabilidade. E que maluco é isso! É muito conveniente defendermos um slogan ecológico no interior de nossas apertadas residências, em meio a um caos urbano no qual somos atacados o tempo todo, até mesmo em nosso tempo privado, por propagandas ${ }^{6}$. A vida saudável, o emblema da sustentabilidade, a defesa da natureza, são conflitos que, no final das contas, se direcionam aos nossos mais profundos interesses individuais. Continuam refletindo, como qualquer objeto de consumo, os efeitos de massa do marketing capitalista.

Mas, retornemos à ideia da defeituosa máquina capitalista devido ao fato de ter sido construída por nós, seres imperfeitos. Inclusive, um paradigma clássico da engenharia informa que sempre existem falhas em qualquer máquina. Serão estes alguns pontos focais para o extravasamento de fluxos de desejo? Existe outra forma de resistir à axiomatização do sistema do capital7? A ideia deste ensaio é apontar uma

também iniciou uma nova linha de produção de seus próprios filmes e séries, adentrando no campo dominado por antigas empresas hollywoodianas e abrindo espaço, inclusive, para estúdios de produção cinematográfica independentes. Estas mudanças são apenas um reflexo de nossa nova concepção de mundo pós-guerra.

${ }^{5}$ Contudo, ressaltamos. A máquina capitalista não se reinventa sozinha, pois ela não é constituída do nada, como um sistema alheio à participação humana. Ao contrário, ela é composta e está em contínuo funcionamento devido à nossa organização social. Isto significa que, quando a máquina se reinventa, na realidade, sua reestruturação é produto da reorganização das máquinas desejantes que nós somos. É interessante observarmos que a dinâmica, a fluidez tão impressionante do capitalismo é devedora da própria interação entre os milhões de fluxos de desejo que o sistema reorienta para se alimentar.

${ }^{6}$ A referência aqui se orienta para as novas formas de marketing que capta dados de nossas atividades diárias, dado que estamos permanentemente conectados, e envia às grandes agências de publicidades e megaempresas para que possam caracterizar seus nichos de mercado. Assim, conseguem elaborar propagandas cada vez mais personalizadas. Além disso, o marketing se tornou tão invasivo ao ponto de se basear nesses dados para propagar conteúdo aos respectivos públicos. Por exemplo, se o nome de uma pessoa for buscado na internet o qual, também for, por acaso, o nome de uma marca de sapatos, é bem provável que propagandas relacionadas a essa marca começarão a aparecer durante nossa navegação na rede.

${ }^{7}$ Deleuze e Guattari (2010, p. 309-310; grifos nossos) afirmam: “[...] toda máquina técnica supõe fluxos de um tipo particular: fluxos de código, ao mesmo tempo interiores e exteriores à máquina, formando os elementos de uma tecnologia e mesmo de uma ciência. São esses fluxos de código que também se encontram encaixados, codificados ou sobrecodificados nas sociedades pré-capitalistas, de tal maneira 
falha, de preferência uma que não tenha sido corrigida em nenhum momento da história. Acerca deste último critério, vale um comentário pessoal: não acredito que o capitalismo não possua uma falha de sistema que seja definitiva. Ainda que ele seja tão flexível a ponto de apagar seus inúmeros defeitos, seria contraditório pensar que ele não só possui capacidade para uma axiomatização absoluta, como também tem uma maleabilidade completa. Isso exigiria que ele fosse, em qualquer um dos casos, perfeitamente eficiente.

A tentativa de delimitar alguma região limítrofe do sistema pode ser vã, mas isso não nos exime do esforço de tentar. Estamos lidando com incertezas e, ainda que elas sejam aberturas verificadas factivelmente pela história, podem não representar um raciocínio coerente com a realidade. Mesmo assim, vale a pena o risco.

Deleuze e Guattari reconhecem a flexibilidade da máquina capitalista por meio

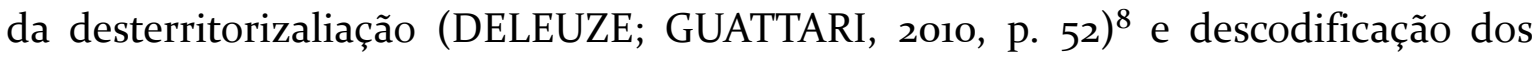
códigos antes vigentes. $\mathrm{O}$ Estado desaparece do centro do mundo, pois até mesmo ele se torna devedor do capital. A dívida se expande, universaliza-se e ninguém escapa dela, nem mesmo o rei. "O Estado já não determina um sistema social, mas é determinado pelo sistema social ao qual se incorpora no jogo de suas funções" (DELEUZE; GUATTARI, 2010, p. 293).

A fluidez do sistema provém do deslocamento, um movimento que acompanha o processo de desterritorialização, o qual, junto com os fluxos descodificados pelo

que eles jamais ganham independência (o ferreiro, o astrônomo...). Mas a descodificação generalizada dos fluxos no capitalismo libertou, desterritorializou, descodificou os fluxos de código, exatamente como o fez com os outros - a tal ponto que a máquina automática os interiorizou cada vez mais no seu corpo ou na sua estrutura como campo de forças, ao mesmo tempo que ela dependia de uma ciência e de uma tecnologia, de um trabalho dito cerebral distinto do trabalho manual do operário (evolução do objeto técnico). Neste sentido, não foram as máquinas que fizeram o capitalismo, mas, ao contrário, o capitalismo é que faz as máquinas e não para de introduzir novos cortes graças aos quais ele revoluciona os seus modos técnicos de produção". A noção de axiomatização implica um esquema de movimento das engrenagens do capital, que exigem certa fluidez de todo o seu sistema. Sendo dinâmico, o capitalismo engloba coisas ao seu interior, tornando-as próprias, parte de sua estrutura. Sua desarticulação se dá pelos processos de desterritorialização e descodificação de fluxos de desejo, que são constantemente reorganizados em favor da grande máquina.

${ }^{8}$ Como o próprio conceito elaborado por Deleuze e Guattari aponta, desterritorializar é sair/remover do território. Este processo tem a ver com libertação, com o se soltar de antigas relações espaciais e com a consequente aderência a novas situações que vão, inclusive, promover mudanças nas próprias conexões entre-máquinas. Carlos Natálio, ao analisar a presença destes processos no interior da dinâmica entre espectador e cinema, compreende que: "Hoje, a noção de desterritorialização aplica-se frequentemente ao enfraquecimento da dimensão espacial da vida em sociedade e fortalecimento das virtualidades. Assim, o conceito serve para definir processos que descontextualizam um número de relações estabelecidas, tornando-as virtuais e preparando-as para novas relações por virtude de uma operação de reterritorialização. Nesse sentido, é comum ver a desterritorialização como tónica da pósmodernidade, sociedades em redes, fluxos e hibridismos culturais. Contudo, trata-se de uma derivação pois a territorialização/desterritorialização surge no trabalho destes autores como conceitos operativos que não só dão a ver o mecanismo das práticas filosóficas e sociais, como reconstroem, reconduzem, a geografia dos eventos num projeto político de libertação dos desejos, dos corpos, da criação artística e produção da subjetividade (Haesbert e Bruce 2002)" (NATÁLIO, 2013, p. 200). 
próprio capitalismo, dão origem à máquina repressora. $\mathrm{O}$ capital se torna o eixo a partir do qual suas engrenagens funcionam, e tudo se organiza em função dele. Desta maneira, a flexibilidade da máquina possui um critério-base: o dinheiro. Neste caso, como parte do processo de desterritorialização, os valores monetários se tornaram abstratos, o que alarga imensamente os horizontes de atuação do capitalismo. Tudo precisa funcionar com base na produção de mais capital, única atividade possível para os fluxos de desejos descodificados. Isto significa que aquilo que não passa pelo critério-base da máquina capitalista não pode ser axiomatizado por ela, a menos que, antes de ser englobada, a nova estrutura seja reformulada com base neste preceitomonetarização. Segue-se então uma possível falha permanente do sistema.

O que ocorre é que a dinâmica do capital impede o acesso a este defeito, reprimindo, com toda a sua potência, a manifestação de quaisquer forças revolucionárias que possam atravessar os limites internos da máquina. Por isso, esta atividade exige uma boa quantidade de reflexão para distinguir possíveis energias que não possam ser suprimidas e transformadas em capital, visto que excedem o alcance restrito - embora interativo - da máquina.

Toda essa infraestrutura do capitalismo nos remete à uma característica intrínseca à sua aparência. A máquina capitalista em si não é concreta, a despeito de funcionar com elementos concretos, reais (p. ex. força de trabalho, mais-valia, produto, salário, mercadoria, propaganda e etc). Ela é, na realidade, abstrata. Devido a isto, se torna uma tarefa bastante difícil determinar com precisão os seus limites e as alterações em sua performance no momento em que acontecem. Assim, com a passagem de um socius anterior (bárbaro) para o novo socius capitalista podemos avaliar que, possivelmente, nem tudo tenha sido incorporado ao novo desenvolvimento social. Resta identificar o que não foi incorporado nem destruído pelo novo sistema.

A hipótese deste ensaio se baseia no fato de que, se a máquina capitalista possui limites, existem coisas que estão fora deles e que não enxergamos. Isto é o que não foi axiomatizado, portanto, são torrentes de desejos que não podem ser utilizadas para alimentar o funcionamento das engrenagens do novo socius. $\mathrm{O}$ indivíduo-máquina, possui duas alternativas perante o sistema do capital: servir de autômato, se rendendo às suas exigências e conformando-se através da conexão de seus cabos com as engrenagens sugadoras de desejos (DELEUZE; GUATTARI, 2010, p. 20), ou ousar ser um esquizofrênico, resistindo e dando vazão aos seus fluxos, transformando-os em forças criativas e revolucionárias (DELEUZE; GUATTARI, 2010, p. 29). Deste modo, será que tais energias podem subsidiar justamente o oposto, o corte de fluxos de desejos que correm em direção ao seio do capitalismo de modo que eles sejam desviados para um extravasamento em massa? Poderia ser ingênuo demais pensar dessa forma, mas não é uma realidade completamente fora de nexo. Se o capitalismo é uma máquina, faz sentido pensar que máquinas podem ser desligadas de diversas 
formas: dentre elas, com o extravio do combustível que as fazem funcionar. Se o capitalismo funciona à base de fluxos de desejos descodificados, a proposta da obra Anti-Édipo é bastante coerente como estratégia de resistência ao programa de atividades do capital.

Uma alternativa seria remover do mundo, abstratamente, as diversas ligações, ferramentas, parafusos, cabos, conectores, que estruturam o capitalismo, que permitem o corte de fluxos, suas descodificações, a desterritorialização (DELEUZE; GUATTARI, 2010, pp. 325-326). No entanto, é interessante perceber que o discurso da máquina capitalista só encontra sentido em suas próprias engrenagens, naquilo que lhe é próprio. Por isso, o mundo é o que a máquina capitalista não consegue axiomatizar, pois, independentemente de seus processos mecânicos, o mundo continua sendo tal como ele é. Ele permanece sendo uma imensa dimensão indefinida em termos de totalidade. Uma máquina imensa que funciona por mecanismos ainda desconhecidos, e a qual recheamos de significados que nem sempre correspondem à sua identidade. Nele encontramos o universo que nos circunda, e compreende toda a nossa realidade material, bem como a própria vida, as relações sociais, o movimento vital de nascimento e da morte.

Neste sentido, é interessante utilizar a compreensão arendtiana de mundo para contrapor à visão deleuzo-guattariana (2010, p. 306; grifos nossos) de uma máquina sem limites externos, como eles explicam: "Se o capitalismo é o limite exterior de toda a sociedade, é porque ele, por sua vez, não tem limite exterior mas tão somente um limite interior que é o próprio capital”. Ora, Arendt (2014, p. 309) descreve esta finitização do mundo em linhas geográficas acessíveis a todos, graças às descobertas científicas, que cumprem a função de colaborar com a dinâmica do capital:

Precisamente no instante em que se descobriu a imensidão do espaço disponível sobre a Terra, começou o famoso apequenamento do globo, até que, em nosso mundo (que, embora resulte da era moderna, não é de modo algum idêntico ao mundo da era moderna), cada homem é finalmente tanto habitante da Terra como habitante do seu país.

As delimitações geográficas foram manipuladas, formando estados, nações, países, cidades e impérios, reunindo pequenos grupos de máquinas ao redor de uma liderança maquínica que funciona a serviço do modo capitalista. O mundo geográfico foi alterado, e as pequenas movimentações comerciais assumiram dimensões cada vez maiores, ultrapassando mares, montanhas e abismos que, outrora, eram impenetráveis (ARENDT, 2014, p. 309). Entretanto, no interior deste mundo, temos planetas, asteróides, satélites, a Terra, a natureza, os animais, cada elemento deste com seu valor vital, com sua engrenagem particular, que ultrapassa as definições maquínicas do capital. Interpretar o capitalismo como uma máquina totalizante seria, no mínimo, reduzir toda esta dimensão ao sentido da monetarização, o que não 
corresponde ao que ocorre de concreto. Nos recordemos que embora a máquina capitalista seja constituída de estruturas e elementos concretos, ela é, em si, abstrata. Ela ainda é uma construção humana e aparenta ser bastante factível, porém, não está muito distante de nossas mentes, nossa imaginação. Além disso, ao afirmar o mundo também apontamos para o seu caráter abstrato, em nível de conceito, que não se limita às suas fronteiras terrestres.

Neste mundo concreto também temos o outro. Todavia, o que atravessa o visar de nossa consciência são os vínculos sociais. Como chamaria Arendt "a teia de relações" (2014, p. 224), que alcançam um nível abstrato e infinito na medida em que a história percorre a sua jornada. Talvez possamos encontrar pequenas garras do capitalismo se aproximando, arduamente, destes vínculos, através das mídias sociais por exemplo. Mas precisamos nos perguntar: até que ponto o Facebook, o Twitter, o Instagram, entre outros, representam a nossa ligação com o mundo, nossa participação nesta teia? Se observarmos atentamente, dificilmente exporíamos nossa cara às pessoas desconhecidas que nos adicionam como 'amigos' de nosso perfil. As relações sociais de um indivíduo são restritas à poucas pessoas, ao sentimento de afinidade, empatia para com o outro. Estas emoções são bloqueadas em grande medida quando estamos no nível virtual, descendo cegamente nossos dedos pelo feeding, e visualizando a máscara do outro. Através delas, também vemos reportagens e, diante da enormidade dos acontecimentos, nos sentimos impotentes, afinal, quem somos nós para ir contra estes acontecimentos?

Pensemos em uma coletividade interligada face-a-face. Nossos amigos, familiares e conhecidos estão vinculados a outras pessoas que, por sua vez, estão ligadas a outros, formando, assim, uma incrível rede humana. Isto é muito abstrato, tanto que, quando agimos, sequer percebemos os fios desta teia reverberando, alcançando pessoas que nem conhecemos. E estes fios são fortalecidos pelo contato humano, pelo conversar, estar com o próximo que, ao mesmo tempo em que está tão perto, está tão distante.

Esta iniciativa reduz a nossa impressão de estarmos solitários no mundo, de sermos um indivíduo, de olharmos permanentemente para nós mesmos, justamente porque ela demonstra que, na realidade, estamos mais interligados do que imaginamos (ARENDT, 2014, p. 65). É a atomização uma das maiores garras da máquina do capital. Ela necessita do isolamento para que possa atuar sobre os fluxos de desejo, cortando-os, pois, por mais que ela possa crescer e seus canos possam aumentar de calibre para suportar cada vez maior pressão, ela é limitada, é imperfeita.

Impressionante é quando conseguimos perceber o outro como aquele de quem dependemos para provocar um extravasamento de fluxos de energia em conjunto. Conforme analisamos, se cada um decidir assumir o seu caráter esquizo inerente à energia revolucionária presente em cada fluxo de desejo, e juntarmos esta força 
extraordinária contra as engrenagens do capital, somos capazes de provocar tamanho extravasamento que poderá comprometer seriamente uma boa parte da estrutura da máquina. Esta é, possivelmente, uma solução eficiente para desarranjar por completo, em termos de efeito dominó, os fluxos de desejo que se dirigem à cápsula de combustível do sistema. Contudo, para que esta iniciativa se torne viável, não adianta olhar para este outro com os óculos do capital, do consumo, do interesse monetário. Ao contrário, devemos realizar um esforço para nos relacionarmos com o mundo, e que tenha origem na vontade individual de sair da casa, retornar à nossa cidade e ocupar o papel de uma cidadania perdida em meio às superficialidades do cotidiano pós-moderno.

É claro que o capitalismo não concederá nenhum conforto a este tipo de posicionamento. Impedir que nossos fluxos de desejos sejam cortados e, ainda por cima, influenciar outros fluxos para que corram na direção contrária é, basicamente, se deslocar da corrente. Olhar para fora dos limites da máquina é desconfortável, incômodo. Mas a perspectiva não é ruim, nem feia, apenas primeva, uma recuperação de um estado que foi oculto pelos movimentos do sistema. A propaganda, imenso pilar do consumo continuará chamando: "Você merece!", "Seja aquilo que você quer ser!", “Experimente!", clichês do marketing capitalista. O objetivo de uma verdadeira propaganda não é incentivar ao consumo, mas propiciar a fidelização, a perigosa dependência, do achar que "eu preciso porque mereço". Se torna, dessa forma, tentador afirmar que merecemos, sim, toda essa conjunção de fluxos descodificados de desejos produzida por ninguém mais além de nós mesmos. E enquanto decidimos se gastamos ou não, o capitalismo já está lá, sem que percebamos, cortando o nosso fluxo de desejos. A própria indecisão já é favorável à dinâmica do sistema.

Deste modo, ser comunidade implica um esforço individual de expandir o núcleo familiar, centrado no modelo tradicional fixado em papai-mamãe-filhinho, de modo a permitir o acesso a outros indivíduos aos estranhos hábitos e costumes familiares. Esta é uma forma de obrigar ao convívio, à abertura, à exposição de falhas humanas, de disputas e dissensos. No entanto, também é uma proposta que motiva a construção de relações, do estar-com-o-outro, do perceber a necessidade da vida coletiva através da expressão do amor, da compaixão, do valor ao próximo. $\mathrm{O}$ mundo se constrói nestas práticas, que não são utópicas e, tampouco, românticas, mas fundamentadas na ideia de que viemos de um lugar, e que essa origem não pode ser apagada (ARENDT, 1997, pp. 54-55). Como avaliamos, talvez esta seja uma permanente falha do sistema do capital.

Assim, podemos afirmar que a máquina capitalista é destrutiva, pois aquilo que ela não consegue englobar, e assim é isolado para ser eliminado. Ela é fluida o suficiente para criar aparências, superfícies de contato que estabelecem uma conexão singular, permeada pelo léxico capitalista. Quem é aquele que não consome? Quem é aquele que não quer se sentir parte do sistema? Quem é aquele que não trabalha? 
Universalizando as coletividades em uma massa única, densa e padronizada, com algumas poucas identidades específicas - que podemos chamar de expressões das minorias como feminismo, LGBT, movimento afro e etc. - o capitalismo se mantém ao longo dos anos. Ele perdura através da própria visão distópica que ele mesmo cria de si, como único caminho histórico, única solução política, única forma de envolvimento social, enfim, única possibilidade de vida.

Mas ele não o é, e todos nós, em algum momento de nossas vidas desconfiamos, ao menos uma vez, disso. Ele é uma das muitas construções humanas, uma mera formação social (socius), um produto da ação conjunta. Sabemos que a própria vida está, além disso, no sentido de que, a própria pertença ao mundo, do vir a ser do mundo e do próprio ser do mundo, implica em superar o que a máquina capitalista é capaz de nos proporcionar.

Talvez, nosso esforço neste ensaio figure demasiado abstrato. Afinal, contrapor à máquina capitalista um espaço que é maior que ela, é, possivelmente, refletir em um nível de abstração que não parece corresponder ao que chamamos de concreto. Mas um dos nossos objetivos era demonstrar o paradoxo no qual a máquina capitalista se insere ao nos impedir de reduzi-la e, ao mesmo tempo, de torná-la grande demais, abstrata demais. Não podemos reduzi-la porque ela não é pequena, porém, não podemos engrandecê-la porque, apesar de tudo, ela continua sendo uma máquina. E como toda máquina, ela está inserida dentro de outra máquina ainda maior e da qual depende: o mundo. Ao delimitá-la, portanto, podemos visualizar que ela não consegue englobar tudo, e uma das coisas que ela não engloba é o nosso sentimento de pertença a um mundo no qual vivemos, no qual o socius reside, e ao qual nunca é superior.

\section{Referências}

ARENDT, Hannah. A Condição Humana. 12 ed. Trad. Roberto Raposo. Rio de Janeiro: Forense Universitária, 2014.

. O Conceito de Amor em Santo Agostinho: ensaio de interpretação filosófica. Trad. Alberto Pereira Dinis. Lisboa: Instituto Piaget, 1997.

CÂNDIDO, Ana Clara. Inovação Disruptiva: Reflexões sobre as suas características e implicações no mercado. Rev. IET Working Papers Series, 2011. Disponível em: https://run.unl.pt/bitstream/10362/6912/1/WPSeries_05_2011ACC\%C3\%A2ndido1.pdf. Acesso em 08 ago. 2017.

DELEUZE, Gilles; GUATTARI, Félix. O Anti-Édipo: Capitalismo e Esquizofrenia 1. Trad. Luiz B. L. Orlandi. São Paulo: Ed. 34, 2010.

Capitalism: A VerySpecial Delirium: entrevista. [1995]. Chaosophy. Entrevista concedida a SylvereLothringer. Disponível em: http://www.generationonline.org/p/fpdeleuze7.htm. Acesso em 10 ago. 2016.

NATÁLIO, Carlos. Territorialização/Desterritorialização: movimentos 
cinematográficos? In: Encontro Anual da AIM, 2., 2013, Lisboa. Atas do II Encontro Anual da AIM. Lisboa: AIM, 2013. p. 199-211. Disponível em:

http://aim.org.pt/atas/pdfs-Atas-IIEncontroAnualAIM/Atas-IIEncontroAnualAIM18.pdf. Acesso em o8 ago. 2017.

Submissão: 03.05.2017 / Aceite: 08.06.2017 